\title{
Separation and Quantification of Sinensetin, Imperatorin and Total Tannin Content as Active Phytoconstituents of Methanol Extract of Imperata cylindrica Root from Kendari
}

\author{
Diah Dhianawaty 1,*, Mas Rizky Anggun Adipurna Syamsunarno' ${ }^{1}$, Resti Gradia Dwiwina ${ }^{2}$, Raden Anita Indriyanti ${ }^{3}$, \\ Ruslin ${ }^{4}$
}

Diah Dhianawaty ${ }^{1, *}$, Mas Rizky Anggun Adipurna Syamsunarno', Resti Gradia Dwiwina², Raden Anita Indriyanti ${ }^{3}$, Ruslin ${ }^{4}$

'Department of Biomedical Sciences, Division of Biochemistry and Molecular Biology, Faculty of Medicine, Universitas Padjadjaran, Bandung, West Medicine, Universitc

Java, INDONESIA. of Cell Biology, Faculty of Medicine, Universitas Padjadjaran, Bandung, West Java, INDONESIA. ${ }^{3}$ Department of Pharmacology, Bandung Islamic University, Bandung, West Java, INDONESIA. ${ }^{4}$ Faculty of Pharmacy, Halu Oleo University, Kendari, Southeast Sulawesi, INDONESIA.

\section{Correspondence}

\section{Diah Dhianawaty}

Department of Biomedical Sciences,

Division of Biochemistry and Molecular

Biology, Faculty of Medicine, Universitas

Padjadjaran, Bandung, West Java,

INDONESIA.

E-mail: dhianawaty@unpad.ac.id

History

- Submission Date: 12-06-2021.

- Review completed: 06-07-2021;

- Accepted Date: 14-07-2021.

DOI : 10.5530/pj.2021.13.155

Article Available online

http://www.phcogj.com/v13/i5

Copyright

(C) 2021 Phcogi.Com. This is an openaccess article distributed under the terms of the Creative Commons Attribution 4.0 International license.

\begin{abstract}
Introduction: Imperata cylindrica root methanol extract harvested from Kendari had anti-hypertensive activity stated in a study on hypertension rat models at the doses 60 and $90 \mathrm{mg} / \mathrm{kg}-\mathrm{bw}$. The extract also contained phenolic compound $1.53 \%$ (GAE) and flavonoid $1.17 \%(\mathrm{OE})$ and had antioxidant activity $I_{50} 0.32 \mathrm{mg} / \mathrm{mL}$. Aim of the study was to determine the active secondary metabolites in the extract. Materials and Method: Sinensetin and imperatorin in the extract were separated on silica gel 60 column, eluted with a gradient eluent system as follows (1) n-hexane- ethyl acetate (3:7); (2) n-hexane - ethyl acetate (2:8); (3) ethyl acetate $-\mathrm{MeOH}(8: 2)$, and (4) methanol. Imperatorin and sinensetin in fractions were identified and quantified by HPLC method with column LiChroCART 250-4,6 RP 18E, isocratic mobile phases with the composition of mixture as follows, $0.1 \%$ formic acid, acetonitrile and methanol (40:50:10) respectively, and at temperature $40^{\circ} \mathrm{C}$. The total tannin was determined by spectrophotometry method with Fe(III) chloride and 1.10-Phenanthroline at wave length $510 \mathrm{~nm}$. Results: Imperatorin and sinensetin were identified in fractions 5 to 9 . The concentrations of sinensetin and imperatorin in Imperata cylindrica root methanol extract were of 32.348 and $37.014 \mathrm{mg} / \mathrm{kg}$ extract, respectively. The total tannin content was $1.06 \%(\mathrm{w} / \mathrm{w})$ (TAE). Conclusion: Imperata cylindrica root methanol extract from Kendari had active phytoconstituents, namely sinensetin, imperatorin, and tannin.

Key words: Imperata cylindrica, Imperatorin, Sinensetin, Tannin.
\end{abstract}

\section{INTRODUCTION}

I. cylindrica root methanol extract from Kendari at the doses 60 and $90 \mathrm{mg} / \mathrm{kg}$-bw was proven to have anti-hypertensive activity based on a study on hypertension rat models.

I. cylindrica is a pernicious grass so that it is regarded as unwanted weed for agricultural land. ${ }^{2}$ In the region of Southeast Asia it can be found about 35 million ha overgrown by grass, and about 8.5 million ha spread in Indonesia. ${ }^{3}$ People consider that it is not beneficial for the environment, but apparently it has a positive role for health. In Indonesian traditional medicine it is used among others for urinary tract infection, hypertension, kidney disease, tonicum, wound, hemorrhoids, fever, cough, etc. ${ }^{3-4}$

The traditional use of $I$. cylindrica is also taken by scientific research to prove its secondary metabolites and pharmacological activities. The scientific studies of secondary metabolites reported I. cylindrica roots contain imperatorin. ${ }^{5}$ Sinensetin; tannins and phenols; lignans; isogeunin; eupatorin; tetra-O-methylscutellar-ein 3'-hydroxy-5,6,7, 4'-tetramethoxyflavone; 5-hydroxy-2- [2- (2hydroxyphenyl) ethyl chromone; imperanene 5-hydroxy-2- (2-phenylethyl) chromone. ${ }^{6}$ Deacetylimpecyloside; impecylone; seguinoside $\mathrm{K}$ 4-methylether; seguinoside K; impecyloside; and impecylenolide. ${ }^{7}$ Hexadecanoic acid; ethyl ester; and cis - 9- Hexadecenal. ${ }^{8}$ isoeugenin (7-hydroxy- 5-methoxy-2-methylchromone);

p-coumaric acid; ferulic acid; caffeic acid. ${ }^{9}$ 4-hydroxybenzene carboxylic acid; 1-O-p-coumaroylglycerol; 1-(3,4,5-trimethoxyphenyl)-1,2,3-propanetriol; 4-methoxy-5-methyl coumarin-7-O-beta-Dglucopyranoside; 3, 4-dihydroxybutyric acid; 3,4-dihydroxybenzoic acid; vanillic acid; salicin; glutinone; arundoin; simiarenol; cylindrin; fernenol. ${ }^{10}$ The aerial part ethyl acetate extract contained tricin; 11, 16-dihydroxypregn-4-ene-3, 20-dione; and 2-methoxyestrone; trans-p-Coumaric acid. ${ }^{11}$ Then, the scientific studies of pharmacological activities reported methanol extract of I. cylindrica roots from Kendari had anti-hypertensive activity on hypertension rat models. ${ }^{1}$ The methanol and mixture of methanol-chloroform leave extracts had activity on E. coli, Enterobacter aerogenes, Proteus vulgaris, S. aureus and Streptococcus albus. ${ }^{8}$ A study on the cats I. cylindrica leaf $70 \%$ hydro ethanol extract showed significant anti-hypertensive activity on cats by dilating and relaxing smooth muscles of blood vessels. ${ }^{12}$ The others pharmacological activities were reported as follows, isoegenin is a potential compound for the therapy of inflammatory diseases, it significantly suppressed proinflammatory cytokines mRNA levels, cyclooxygenase-2 (COX-2), and the LPS-induced expressions of inducible nitric oxide synthase (iNOS). ${ }^{9}$

Sinensetin showed vasorelaxant effect in in vitro on the aortic ring through several pathways included the nitric oxide/guanyl cyclase/cyclic 3',5'-guanosine 
monophosphate (NO/sGC/cGMP) pathway, potassium and calcium channels. ${ }^{13}$ Imperatorin is one of the major active coumarins found in the root of I. cylindrica ${ }^{5}$, had anti-hypertensive activity on mice; it showed a significant decrement in systolic and diastolic blood pressures. ${ }^{14}$ Imperatorin also prevents cardiovascular diseases by way of the impediment of hypertension ${ }^{15}$, as well tannic acid activity has been observed in hypertensive rats, and tannic acid showed a reducing activity on blood pressure. ${ }^{16}$

Based on the previous studies as stated on the above, it was found that compounds that have anti-hypertensive activity in I. cylindrica included sinensetin, imperatorin, and tannin. Therefore, a study on the I. cylindrica root methanol extract from Kendari that had antihypertensive activity was continued to examine its content which was active to decrease blood pressure, namely sinensetin, imperatorin, and tannin.

\section{MATERIALS AND METHODS}

\section{Materials}

Methanol extract of I. cylindrica roots was grown in Kendari (Southeast Sulawesi). Sinensetin and imperatorin reference standards were from ChemFaces; Tannic acid and 1,10-phenantrolin from Sigma Aldrich; formic acid; methanol; acetonitrile; and Milli Q-water (Merck) (all reagents were HPLC grade), ethylenediaminetetraacetic acid (EDTA), iron (III) chloride hexahydrate, sodium chloride, hydrochloric acid, gelatine, sulfuric acid, acetic acid, sodium acetate, n-hexane, aethylacetate and silica gel $60 \mathrm{H}$ from Merck (all reagents were analytical grade).

\section{Equipment}

The equipment were used to examine the extract as follows, Waters Alliance e2695 HPLC; detector UV/Vis 2489, Column: LiChroCART 250-4,6 RP 18E wave length: UV $254 \mathrm{~nm}$. Glass column for column chromatography, Eppendorf Biospectrometer Basic AG 22331 Hamburg series: $6135 \mathrm{BJ}$.

Quantification of sinensetin and imperatorin by High performance liquid chromatography (HPLC).

\section{Preparation of sinenestin and imperatotin separation by column chromatography ${ }^{17}$}

The methanol extract of I. cylindrica roots weighed $150 \mathrm{mg}$, and sinensetin and imperatorin in the extract were separated on a silica gel $60 \mathrm{H}$ column using a gradient eluent system, as follows: (1) a mixture of n-hexane - ethyl acetate (3: 7); (2) a mixture of n-hexane - ethyl acetate (2: 8); (3) a mixture of ethyl acetate-methanol (8: 2); (4) methanol, respectively.

\section{Preparation of sample and reference standards for HPLC analysis $^{18-19}$}

Samples as fractions resulted from column chromatography (12 fractions) aliquot of each fraction was dissolved in $10 \mathrm{ml}$ methanol and filtered through a Millipore $0.45 \mu \mathrm{m}$ filter. Then, $10 \mu \mathrm{L}$ of every fraction was taken and injected to HPLC instrument. In the same way with the fraction procedure, both sinensetin and imperatorin reference standard compounds were weighed in the concentrations as follow: $10,20,30,40$ and $50 \mathrm{mg}$, respectively; the reference standards were dissolved in $10 \mathrm{ml}$ of methanol and then filtered through a Millipore $0.45 \mu \mathrm{m}$ filter. Then, $10 \mu \mathrm{L}$ was injected to HPLC instrument.

The condition of samples analysis was as follows, a column LiChroCART 250-4,6 RP $18 \mathrm{E}$ with heating at $40{ }^{\circ} \mathrm{C}$ was used as stationary phase and eluted with an isocratic mobile phases consist of $0.1 \%$ formic acid in water - acetonitrile - methanol (40:50:10). Flow rate was 1 $\mathrm{ml} / \mathrm{min}$, separation time was $18 \mathrm{~min}$, and detection was at $254 \mathrm{~nm}$. Chromatogram data result was performed with the aid of sma4w148e.

Furthermore, in the same condition with the samples, reference standard curves of sinensetin and imperatorin were measured by various concentrations: $10,20,30,40$, and $50 \mathrm{ppm}$, respectively. Standard calibration curves were established by plotting the peak area against retention time

\section{MEASUREMENT OF TOTAL TANNIN IN THE EX- TRACT $^{20}$}

\section{Preparation of reference standarsd calibration curve}

Reference standard tannic acid $(100 \mathrm{ug} / \mathrm{mL})$ was pipetted to 25.00 $\mathrm{mL}$ the volumetric flasks as follows: $0.125 ; 0.250 ; 0.500 ; 0.750$ and 1 $\mathrm{mL}$, respectively. The final concentration of each reference standard tannic acid was $0.5,1.0,2.0,3.0$ and $4.0 \mu \mathrm{g} / \mathrm{mL}$. Each flash was added $2.50 \mathrm{~mL}$ of iron (III) chloride hexahydrate solution $(0.01 \mathrm{~mol} / \mathrm{L})$ and the mixture was incubated at $80{ }^{\circ} \mathrm{C}$ in a water bath for 20 minutes. Afterwards, each flash was added $2.50 \mathrm{~mL}$ of acetic buffer $(\mathrm{pH} 4.4$ ), $5.0 \mathrm{~mL}$ of 1,10 -phenanthroline solution $(0.015 \mathrm{~mol} / \mathrm{L})$ and $0.50 \mathrm{~mL}$ of EDTA $(0.05 \mathrm{~mol} / \mathrm{L})$ let the solution cool. Then, each flash was added up with distilled water to the limit mark. The solution absorbance was measured at a wavelength of $540 \mathrm{~nm}$ relative to the blank.

The reference standard calibration curve was made by plotting the absorbance against concentration.

\section{Preparation sample of $I$. cylindrica roots extract}

The I. cylindrica roots extract was prepared by dissolving 0.025 grams extract to $100 \mathrm{ml}$ of distilled water (was called extract "A" solution). Aliquots of $10 \mathrm{ml}$ of extract A was pipetted to $25.00 \mathrm{~mL}$ volumetric flasks, and the next step followed the steps in the calibration curve preparation.

\section{Preparation of blank for I. cylindrica root extract}

Aliquots of $10 \mathrm{ml}$ of extract "A" solution was pipetted to $100.00 \mathrm{~mL}$ volumetric flasks which were previously added $0.50 \mathrm{~mL}$ of gelatine solution $(0.3 \% \mathrm{~m} / \mathrm{V}), 10 \mathrm{~mL}$ of acidic $\mathrm{NaCl}$ solution. The mixture in the flask was shaken and filtered (was called Fitrat No.1); Fitrat No.1 was pipetted again of $10 \mathrm{ml}$ and then a similar way to Fitrat No.1 procedure was done at which the result was called Filtrate No. 2.

The Filtrate No. 2 was treated such as the standard of tannic acid and samples of I. cylindrica extract.

\section{Preparing the gelatin blank}

The gelatine blank samples were made with the same procedure as the blank I. cylindrica samples. The sample of I. cylindrica was changed with distilled water.

All works were carried out three repetitions, and the absorbance of the solutions above were measured at a wavelength of $540 \mathrm{~nm}$.

The tannin content was calculated with the equation bellow:

Anbs $=$ Abbs - Agbs

At $=$ As - Anbs

where: Anbs = absorbance of the net blank samples,

Abbs = absorbance of the blank I. cylindrica samples and

Agbs = absorbance of the gelatine blank sample for the corresponding sample.

At $=$ absorbance presents the absorbance of the tannins in the sample 
As = absorbance of the I. cylindrica sample.

Then total tannin content was calculated from At and equation of calibration curve of standard reference of tannic acid.

\section{Time and place}

This study had been carried out in the period of November 2020 - Maret 2021 in Central Laboratory Universitas Padjadjaran and Biochemistry and Molecular Biology Laboratory Faculty of Medicine Universitas Padjadjaran, Jatinangor, Indonesia.

\section{RESULT}

\section{Separation and quantification of Sinensetin and Imperatorin from I. cylindrica extract}

Measurement of sinensetin and imperatorin in the extract by HPLC showed the present of sinensetin with the following data: RT: 5.700; area: 1517, and imperatorin, RT: 9.976; area: 6723 .

Based on these data, the extract was developed with column chromatography method to separate sinensetin and imperatorin. Separation with column chromatography ${ }^{17}$ resulted 12 fractions from F-1 to F-12, each fraction contained the different bands; the weight and the color of each fraction were shown in the Table 1.

All fractions (12 fractions consisted of F-1 to F-12) which were resulted from column chromatography were weighed as follows from F-1 to F-12: $0.0006 ; 0.0106 ; 0.0068 ; 0.0194 ; 0.0102 ; 0.0016 ; 0.0032 ; 0.0154$; $0.0023 ; 0.0410 ; 0.0466$; and $0.0531 \mathrm{mg}$, respectively. Then, sinensetin and imperatorin content in the 12 fractions were identified by HPLC. Result of the measurement was retention time which was shown in the Figure 1 and Figure 2.

Figure 1 showed chromatograms of F- 4 to F- 6 , at the F- 4 chromatogram sinensetin and imperatorin were not identified. This meant that from the F-1 to the F-4 did not contain sinensetin and imperatorin. The F-5 chromatogram had shown sinensetin and imperatorin began to be identified.
Figure 2 showed chromatograms of F-9 contained sinensetin and imperatorin, at the F-10 sinensetin and imperatorin were not identified. This meant from the F-10 to F-12 did not contain sinensetin and imperatorin, and the last fraction that contained sinensetin and imperatorin F-9.

Based on Figure 1 and Figure 2 above, the results of fractionation by using column chromatography and measurement by HPLC showed that fraction- 5 to fraction- 9 contained sinensetin and imperatorin.

\section{Quantification of sinensetin and imperatorin by HPLC method}

Reference standard curves of sinensetin and imperatorin were made by various concentrations: $10,20,30,40$, and $50 \mathrm{ppm}$, respectively. The resulted areas of both reference standards in various concentration above, limits of detection (LOD), and limits of quantification (LOQ) were shown in Table 2, while the reference standard curves were shown in the Figure 3 and Figure 4, respectively.

Equation of the reference standard curve of sinensetin was $y=21021 x$ - 47055, and imperatorin of $y=45060 x-96710$.

Both equations were used to calculate the concentration of sinensetin and imperatorin in the fractions (F-5 to F-9), respectively. The sinensetin and imperatorin content in each fraction were shown in the Table 3.

From the sum of F5 to F9 in the Table 3 presented total concentrations of sinensetin and imperatorin in the extract were 32.348 and 37.014 $\mathrm{mg} / \mathrm{kg}$ extract, respectively.

\section{Quantification of total tannin in I. cylindrica roots extract}

Calculation of tannin content required measurements of absorbances of the extract, blank of extract, gelatine blank, respectively. The absorbances were used to calculate As (the absorbance of the $I$. cylindrica extract). Furthermore, total tannin content was calculated by using As and the equation of calibration curve of tannic acid reference standard.

Table 1: Weight and color of 12 Fractions (F1 to F12) resulted from column chromatography of $l$. cylindrica roots extract.

\begin{tabular}{|c|c|c|c|c|c|c|}
\hline \multirow{2}{*}{$\begin{array}{l}\text { Fraction } \\
\text { name }\end{array}$} & \multirow[b]{2}{*}{ Separation result } & \multicolumn{4}{|c|}{ Eluents (gradient) } & \multirow{2}{*}{$\begin{array}{c}\text { The result of } \\
\text { separation from the } \\
\text { column }\end{array}$} \\
\hline & & $\begin{array}{l}\text { Ethyl acetate-n- } \\
\text { hexan (7:3) }\end{array}$ & $\begin{array}{l}\text { Ethyl acetate-n- } \\
\text { hexan }(8: 2)\end{array}$ & $\begin{array}{l}\text { Ethyl acetate- } \\
\text { methanol }(8: 2)\end{array}$ & Methanol & \\
\hline $\mathrm{F} 1$ & clear & $\mathrm{v}$ & & & & \\
\hline $\mathrm{F} 2$ & greenish yellow & $\mathrm{v}$ & & & & F2 \\
\hline F3 & light brown & $\mathrm{v}$ & & & & \\
\hline $\mathrm{F} 4$ & light brown & $\mathrm{v}$ & & & & \\
\hline F5 & light brown & $\mathrm{v}$ & & & & F3-F6 \\
\hline F6 & light brown & $\mathrm{v}$ & & & & \\
\hline F7 & brownish & $\mathrm{v}$ & & & & F7 \\
\hline F8 & light brown & $\mathrm{v}$ & & & & F8 \\
\hline F9 & light brown & & $\mathrm{v}$ & & & F9 \\
\hline F10 & yellow ( $1^{\text {st }}$ band) & & & $\mathrm{v}$ & & $\begin{array}{l}\text { F10 } \\
\text { F11 }\end{array}$ \\
\hline F11 & yellow ( $2^{\text {nd }}$ band) & & & $\mathrm{v}$ & & \\
\hline F12 & light brown & & & & $\mathrm{v}$ & \\
\hline
\end{tabular}




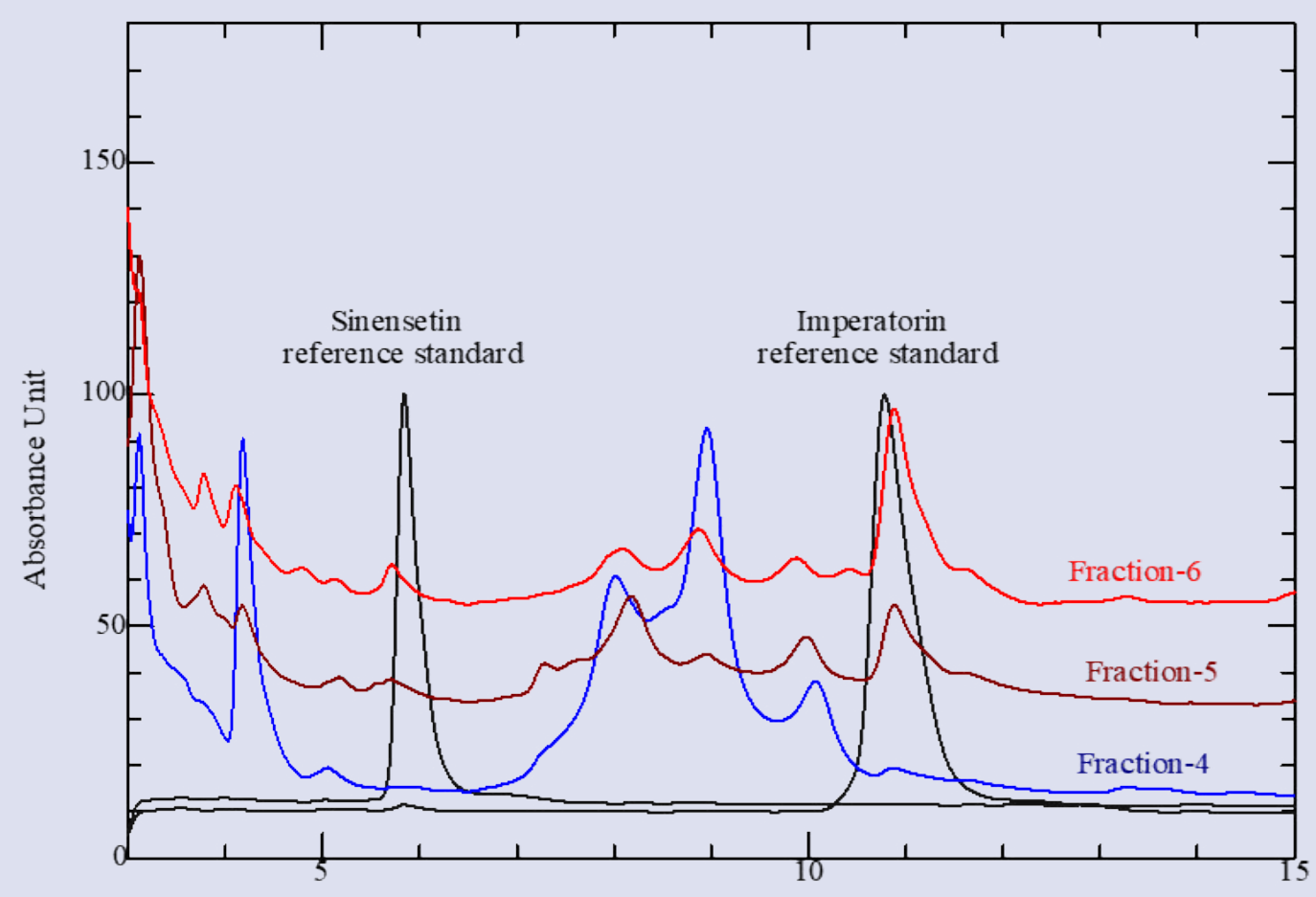

Retention Time (min)

Figure 1: Chromatograms of reference standards of sinensetin and imperatorin and the Fraction-4 to the Fraction-6.

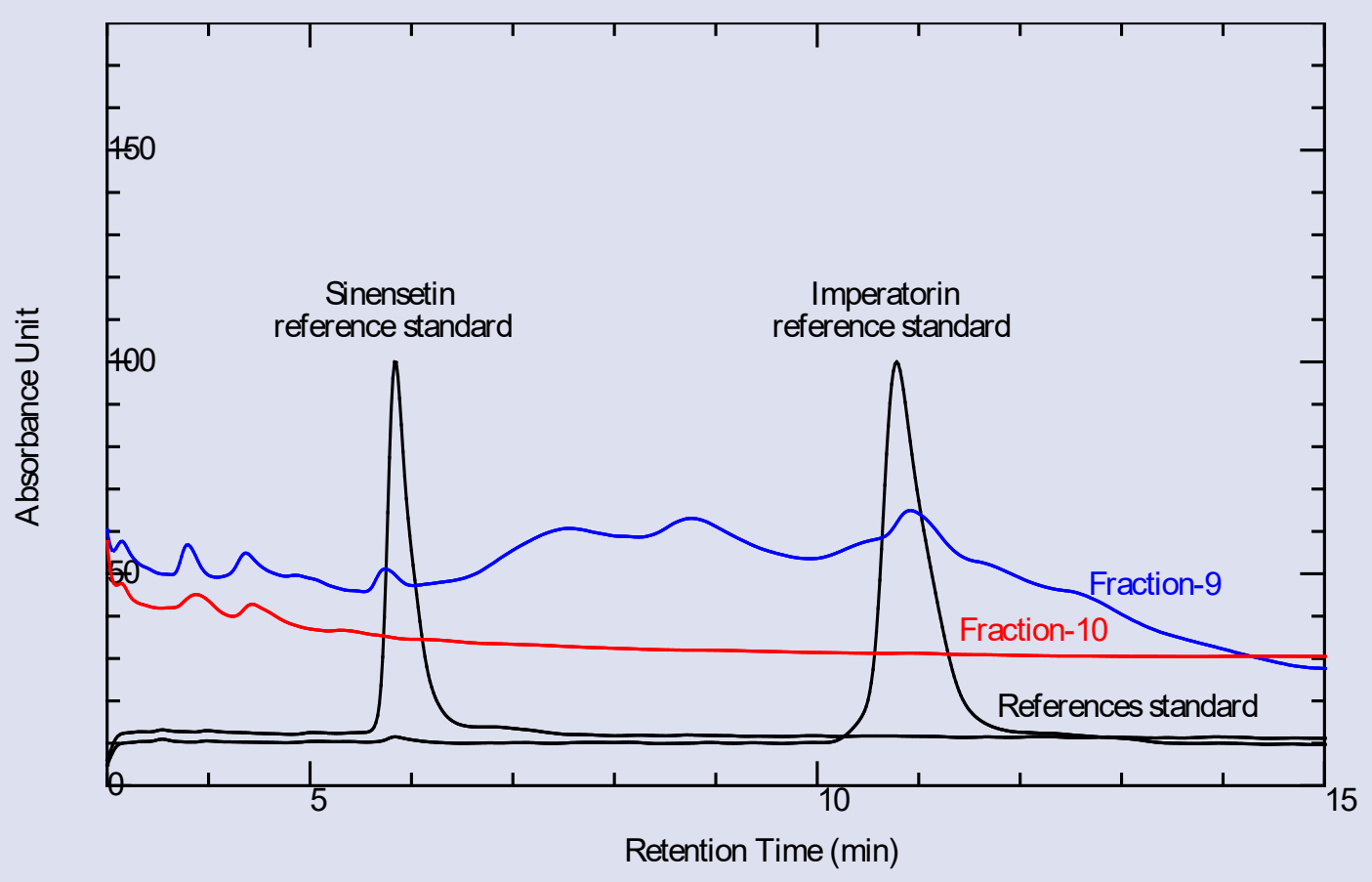

Figure 2: Chromatograms of reference standards of sinensetin and imperatorin and the Fraction-9 and the Fraction-10. 
The absorbances included extract, blank of extract, and gelatine blank were shown in the Table 4.

Absorbances as the results from measurement of extract, blank of extract, and gelatine blank were used to calculate absorbance of the $I$. cylindrica extract (As) by the following equations:

Anbs $=$ Abbs - Agbs

At $=$ As - Anbs

The result: As $=0,558$

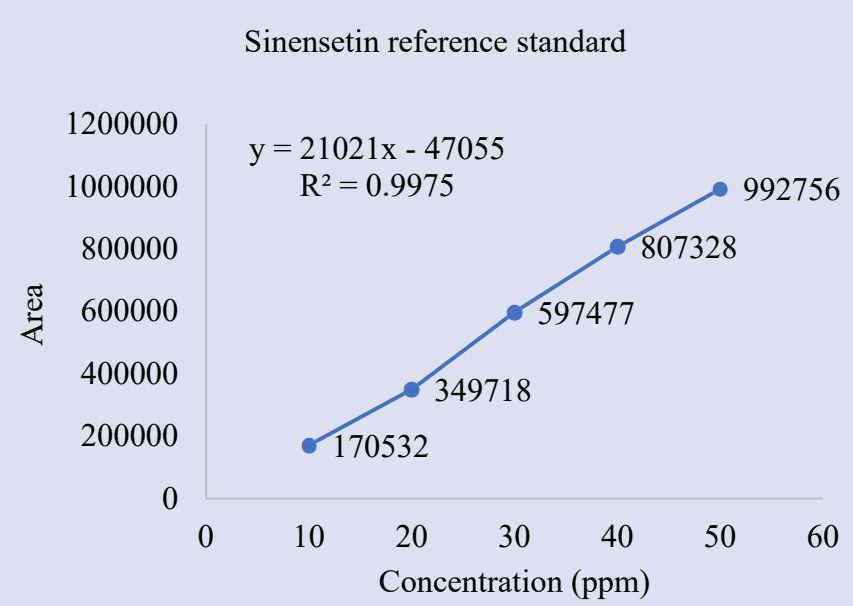

Figure 3: The standard curve of sinensetin reference standard in various concentration of $10,20,30,40$ and 50 ppm.

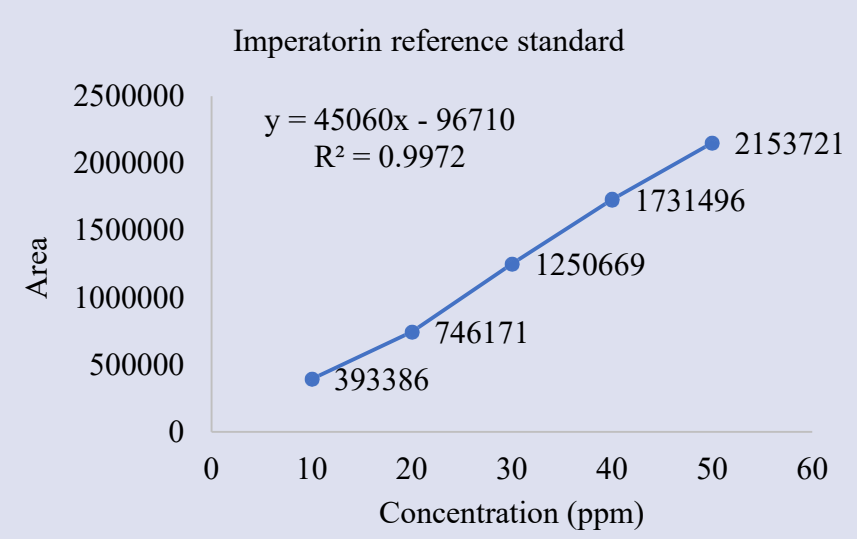

Figure 4: The standard curve of imperatorin reference standard in various concentration of $10,20,30,40$ and $50 \mathrm{ppm}$.

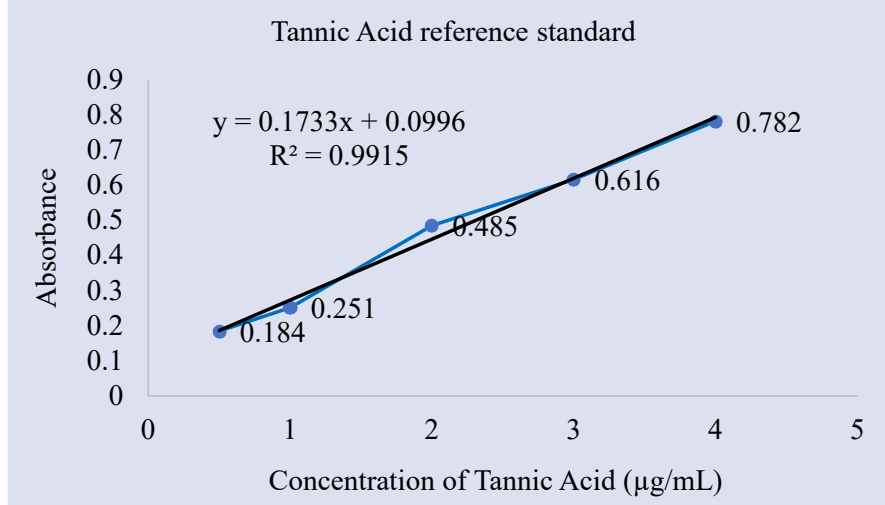

Figure 5: Calibration curve of tannic acid reference standard.
Table 3: The content of sinensetin and imperatorin in each fraction (F5F11) of $I$. cylindrica roots extract.

\begin{tabular}{|c|c|c|c|c|c|c|}
\hline \multirow[b]{2}{*}{ Fraction } & \multicolumn{3}{|l|}{ Sinensetin } & \multicolumn{3}{|c|}{ Imperatorin } \\
\hline & $\begin{array}{l}\text { Retention } \\
\text { time }\end{array}$ & Area & $\begin{array}{l}\text { Concentration } \\
\text { (ppm) }\end{array}$ & $\begin{array}{l}\text { Retention } \\
\text { time }\end{array}$ & Area & $\begin{array}{l}\text { Concentration } \\
\text { (ppm) }\end{array}$ \\
\hline $\begin{array}{l}\text { Reference } \\
\text { standard }\end{array}$ & 5.842 & & & 10.784 & & \\
\hline F5 & ND & ND & - & 10.884 & 6628 & 2248.37 \\
\hline F6 & 5.713 & 1349 & 14391.56 & 10.883 & 10710 & 14899.58 \\
\hline F7 & 5.714 & 1803 & 7263.27 & 10.886 & 22640 & 8277.16 \\
\hline F8 & 5.746 & 8422 & 1713.72 & 10.948 & 46588 & 2065.04 \\
\hline F9 & 5.742 & 2023 & 8979.67 & 10.919 & 14867 & 9523.80 \\
\hline F10 & ND & ND & - & ND & ND & - \\
\hline F11 & ND & ND & - & ND & ND & - \\
\hline Total & & & 32348.22 & & & 37013.95 \\
\hline
\end{tabular}

Note: $\mathrm{ND}=$ not detected

Table 2: Area of sinensetin and imperatorin reference standards in concentrations of $10,20,30,40$, and 50 ppm, and limits of detection (LOD) and limits of quantification (LOQ).

\begin{tabular}{lcc|}
\hline $\begin{array}{l}\text { Standard concentration } \\
(\mathrm{ppm})\end{array}$ & \multicolumn{2}{c}{ Area of reference standards } \\
\cline { 2 - 3 } 10 & Sinensetin & Imperatorin \\
20 & 170532 & 393386 \\
30 & 349718 & 746171 \\
40 & 597477 & 1250669 \\
50 & 807328 & 1731496 \\
LOD & 992756 & 2153721 \\
LOQ & 1.3530 & 1.4812 \\
& 4.1000 & 4.4886
\end{tabular}

Table 4: Absorbance of extract, blank of extract, and gelatine blank.

\begin{tabular}{lc}
\hline Sample & Absorbance \\
\hline I. cylindrica extract & 0,653 \\
Blank of $I$. cylindrica extract & 0,164 \\
Blank of gelatine & 0,069
\end{tabular}

Table 5: Calibration curve of tannic acid reference standard.

\begin{tabular}{cc}
\hline $\begin{array}{c}\text { Concentration } \\
\mu \mathrm{g} / \mathrm{mL}\end{array}$ & Absorbance \\
\hline 0.5 & 0.184 \\
1 & 0.250 \\
2 & 0.482 \\
3 & 0.615 \\
4 & 0.784 \\
\hline
\end{tabular}

The Calibration curves of tannic acid reference standard in various concentrations were $0.5,1.0,2.0,3.0$ and $4.0 \mu \mathrm{g} / \mathrm{mL}$ respectively, and the equation of calibration curve shown in Table 5 and Figure 5.

Then, the tannin content was calculated from As and the equation of calibration curve of tannic acid reference standard.

The equation showed $y=0.1733 \mathrm{x}+0.0996$ and $\mathrm{As}=0,558$, the total tannin content as equivalent of tannic acid in I. cylindrica roots extract $=1.06 \%(\mathrm{w} / \mathrm{w})(\mathrm{TAE})$.

\section{DISCUSSION}

A previous study by Ruslin proved the methanol I. cylindrica root extract from Kendari at the doses of 60 and $90 \mathrm{mg} / \mathrm{kg}$-bw has been proven to have anti-hypertensive activity. ${ }^{1}$

Hypertension (HT) or high blood pressure is a major risk factor for cardiovascular disease and related complications, such as heart disease, 
kidney damage, eye damage and stroke. ${ }^{21-22}$

Hypertensive cases can occur due to genetic factors, several environmental and behavior factors such as obesity, high-salt intake, insulin resistance, stress and low physical activity levels. There are several mechanisms involved in maintaining normal blood pressure among others, renin-angiotensin-aldosterone system, sympathetic nervous system, endothelial function plus water and sodium retention. Hypertension is classified into primary (or essential) and secondary hypertension; the primary hypertension has a relation to salt intake rise and overweightness and shows a strong correlation with family history. The secondary hypertension is associated with several diseases including sleep apnoea, chronic kidney disease, adrenal diseases, and renal artery stenosis. A usual occurrence in both states is multiple mechanism imbalances in maintaining normal blood pressures as such, renin-angiotensin-aldosterone system, sympathetic nervous system, endothelial function plus sodium and water retaining. Two major factors which maintain normal blood pressures are cardiac output and peripheral vascular resistance (PVR). It determines that increased cardiac output caused by sympathetic dysfunction becomes a leading cause of hypertension and PVR increase is the physiologic reaction to accommodate alteration of blood pressure and maintain homeostasis. The renal sympathetic nervous system SNS plays a major role in the development and maintenance of blood pressure by two pathways, namely, the afferent and efferent pathways. The efferent pathway involves signaling from the SNS to the kidney, releases of renin, and is followed by activation the renin-angiotensin-aldosterone system (RAAS) and increases sodium and water retention; all conditions cause an increase in circulating volume leading to blood pressure increase. The RAAS system becomes a main factor in the process of normal blood pressure maintenance. A significant relation between endothelial dysfunction level and severity of hypertension was found. A main mechanism for endothelial dysfunction discovered in hypertension is availability decline of nitric oxide (NO) due to oxidative stress increase. Vasoactive substances, endothelin is secreted by endothelial cells, a strong vasoconstrictor which is one of the primary substances in the process of vascular tone maintenance..$^{23}$

Based on the theory above, two major factors in maintain normal blood pressures are cardiac output and PVR. Ruslin has proven I. cylindrica root methanol extract caused a decrease in cardiac output in hypertensive rat models. ${ }^{1}$ Therefore, the activity of extract in lowering blood pressure is in accordance with the above theory.

Likewise with increased oxidative stress, Dhianawaty and Ruslin had proven I. cylindrica root methanol extract to have antioxidant activity $\mathrm{IC}_{50} 0.32 \mathrm{mg} / \mathrm{mL} .{ }^{25}$ Therefore, the extract can prevent the increase in oxidative stress, thus the increase in blood pressure can be prevented and the activity of extract in lowering blood pressure is in accordance with the above theory.

Previous studies reported many plants have anti-hypertensive activity. This activity was caused by secondary metabolites content, such as sinensetin caused relaxation of the rat aortic ring precontracted with phenylephrine (PE). Sinensetin also showed the relaxant stimulated in present of the others contracted compounds on rat aortic ring such as methylene blue (cyclic guanosine monophosphate lowering agent), $\mathrm{N} \omega$-nitro-L-arginine methyl ester (nitric oxide synthase inhibitor), etc.

The study showed sinensetin had vasorelaxant activity among other which engage the $\mathrm{NO} / \mathrm{sGC} / \mathrm{cGMP}$ and indomethacin pathways, muscarinic and beta-adrenergic receptors, and calcium and potassium channels. ${ }^{13}$ Imperatorin is an active furocoumarin which has been proven to have vasodilatory activity. Antioxidant activity of imperatorin was reported to cause anti-hypertensive activity due to renal injury prevention by (1) reducing Nicotinamide adenine dinucleotide phosphate (NADPH) oxidase, because it is a main source of ROS in hypertension, and (2) inhibiting or downregulating mitogen-activated protein kinase (MAPK) pathway, since this pathway can increase reactive oxygen species (ROS). ${ }^{24}$ Tannic acid showed the activity in lowering blood pressure in L-NNA-induced hypertensive rats. ${ }^{16}$

Sinensetin, imperatorin, and tannin are phenolic compounds. The term phenolic compound includes a wide range of plants substances which have in common an aromatic ring bearing one or more hydroxyl substituents. Phenolic compound is divided into 8 classes such as phenol and phenolic acids: phenylpropanoids, flavonoid pigments, anthocynins, flavonol and flavones, minor flavonoids, xanthones and stilbenes, tannin, and quinone pigments. Based on the above classification, the three compounds to be identified are included in the following class: sinensetin is a flavone; imperatorin is a coumarin belonging to the phenylpropanoid class; and tannins. ${ }^{25}$

Based on the study as stated on the above, sinensetin (methylated flavone), imperatorin, and tannin are secondary metabolites of $I$. cylindrica which had anti-hypertensive activity ${ }^{12-16}$, all of which are phenolic compounds, and methanol extract of the root of I. cylindrica from Kendari have been reported to contain polyphenols, the total polyphenol and flavonoid contents were of $1.53 \%$ gallic acid equivalent (GAE) and $1.17 \%$ quercetin equivalent (QE), respectively. ${ }^{25-26}$

The study was continued by investigating the phytochemical content of the extract. The extract included sinensetin, imperatorin, and tannin. The examination of sinensetin and imperatorin reference standards using the HPLC method showed the retention times of 5.842 and $10.784 \mathrm{~min}$, respectively (Table 3 ). The retention times of sinensetin and imperatorin in the fraction of the extract were in the range of 5.713 to 5.742 and 10.884 to $10.919 \mathrm{~min}$, respectively (Table 3). Retention time similarity of both reference standards and sinensetin, and imperatorin in the fractions of extract were depicted in Figure 1 and Figure 2 (all chromatograms in Figure 1 and Figure 2 were performed with the aid of sma4w148e).

Similarity of all retention times among of sinensetin, and imperatorin reference standards were 5.842 and $10.784 \mathrm{~min}$, while sinensetin and imperatorin in fraction from I. cylindrica roots methanol extract were in the range of 5.713 to 5.742 , and 10.884 to $10.919 \mathrm{~min}$. The concentrations of sinensetin and imperatorin in I. cylindrica roots methanol extract were 32.348 and $37.014 \mathrm{mg} / \mathrm{kg}$ extract, respectively. Likewise the tannin content, the extract contained $1.06 \%(\mathrm{w} / \mathrm{w})$ (TAE).

As described on the above the examination of sinensetin and imperatorin using the HPLC method on the extract proved that I. cylindrica roots methanol extract contained sinensetin, and imperatorin. Similar to tannins, examination of the extract with spectrometric method proved that the extracts contained tannins. The I. cylindrica roots methanol extract can be proven to contain sinensetin, imperatorin, and tannin.

Thus, the anti-hypertensive activity of I. cylindrica root methanol extract can be supposed from these three compounds, as previously explained, the way of sinensetin decreases the blood pressure was through the NO/sGC/cGMP pathway. This pathway regulates blood pressure homeostasis by influencing sympathetic nervous system, vascular tone, and sodium and water handling in the kidney. ${ }^{13}$ Then, imperatorin can stimulate vasorelaxation effect via activated of antioxidant activity which was further explained that antioxidant activity of imperatorin stimulate anti-hypertensive activity by prevention of renal injury that was caused by activation of p38 MAPK pathway, and increase of $(\mathrm{NADPH})$ oxidase. $^{24}$

The I. cylindrica roots methanol extract was reported to have antioxidant activity with IC50 $0.32 \mathrm{mg} / \mathrm{mL}^{25}$ and the $3^{\text {rd }}$ compound namely tannin showed inhibition activity on AT1R gene expression and cellular response. If the Angiotensin II (AngII) binds AT1R, this condition will cause most pathological effects (among other hypertension). Therefore, 
tannin has activity to protect pathological condition and reduces mortality by blocking the AT1R. ${ }^{27}$

The sinensetin, imperatorin, and tannin content in the extract has supported the anti-hypertensive activity. The presence of sinensetin $(32.348 \mathrm{mg} / \mathrm{kg}$ extract), imperatorin $(37.014 \mathrm{mg} / \mathrm{kg}$ extract), and tannin $[1.06 \%(\mathrm{w} / \mathrm{w})]$ can be used as a typical characteristic of $I$. cylindrica roots methanol extract which has activity as anti-hypertension.

\section{CONCLUSION}

This study proved that the I. cylindrica roots methanol extract contained sinensetin, imperatorin, and tannin. These three compounds in previous studies were reported to have activity to lower blood pressure, thus the presence of all three phytoconstituents in the extract could support the anti-hypertensive activity of the extract.

Therefore, exactly to develop the extract of I. cylindrica roots in the future, sinensetin, imperatorin, and tannin can be used as three active phytoconstituents parameters of the extract which have an activity to inhibit the increasing of blood pressure.

\section{ACKNOWLEDGE}

The authors thank to staffs of Central Laboratory and Biochemistry and Molecular Biology Laboratory Universitas Padjadjaran, Jatinangor, Indonesia.

\section{CONFLICTS OF INTEREST}

The authors declare no conflicts of interest.

\section{REFERENCES}

1. Ruslin, Asmawi MZ, Rianse Usman, Sahidin, Dhianawaty D, et al. Anti-hypertensive activity of Alang-alang (Imperata cylindrica (L) Beauv. root methanolic extract on male Wistar rat. J Rs Pharm Sci. 2013;4(4):537-542

2. Centre for Agriculture and Bioscience International (CABI). Invasive species compendium, Imperata cylindrica (cogon grass). 2019. Nairobi (Kenya): National Museums of Kenya; 2019.

3. Hidayat S, Rachmadiyanto AN. Utilization of alang-alang (Imperata cylindrica (L.) Raeusch.) as traditional medicine in Indonesian Archipelago. Science and Technology Research Partnership for Sustainable Development Program The $1^{\text {st }}$ SATREPS Conference; 2016 Nov 14; Bogor, Indonesia: Center for Plant Conservation Botanic Gardens; 2016:82-9.

4. Dalimarta. Atlas of Indonesian medicinal plants. In: Aby Nahdah, Zariyal, Editors. Alang- alang (Imperata cylindrica [L] Beauv). Depok: Puspa Swara, p. 1-3; 2010.

5. Zheng YM, Lu AX, Shen JZ, Kwok AHY, Ho WS. Imperatorin exhibits anticancer activities in human colon cancer cells via the caspase cascade. Oncology Reports. 2016;35:1995-2002.

6. Zulkarnain Z, Wijayanti E, Fitriani U, Triyono A. Literature study to obtain the scientific basis for the use of Imperata roots as a medicinal herb for healing several diseases in Rumah Riset Jamu Hortus Medicus. Media Litbangkes. 2019;29(4):329-40.

7. Liu X, Zhang B, Chou G, Yang L, Wang Z. Chemical constituents from Imperata cylindrica. China Journal of Chinese Materia Medica. 2012 Aug;37(15):2296-300.

8. Oji N, Alaekwe IO, Ajiwe VIE, Aningo GN, Lackson A. Evaluation of the medicinal properties of Imperata cylindrica (Ata) leaf. World Journal of Pharmaceutical and Life Sciences. 2017; 3(7):05-10.

9. An H-J, Nugroho A, Song BM, Park HJ. Isoeugenin, a novel nitric oxide synthase inhibitor isolated from the rhizomes of Imperata cylindrica. Molecules 2015, 20(12), 21336-45.
10. Liu X, Zhang BF, Yang L, Chou GX, Wang ZT. Four new compounds from Imperata cylindrica. J Nat Med. 2014;68(2):295-301.

11. Wang Y, Shen JZ, Chan YW, Ho WS. Identification and growth inhibitory activity of the chemical constituents from Imperata cylindrica aerial part ethyl acetate extract. Molecules. 2018;23:1-13.

12. Mak-Mensah E, Komlaga G, Terlabi EO. Antihypertensive action of ethanolic extract of Imperata cylindrica leaves in animal models. J. Med. Plant Res.2010;4(14):1486-91.

13. Yam MF, Tan CS, Shibao R. Vasorelaxant effect of sinensetin via the NO/sGC/cGMP pathway and potassium and calcium channels. Hypertension Research.2018;8(15):1-11.

14. Koziol E, Skalicka-Woz'niak K. Imperatorin-pharmacological meaning and analytical clues: profound investigation. Phytochem Rev. 2016;15:627-49.

15. Nasser MI, Zhu S, Hu H, Huang H, Guo M, Zhu P. Review: Effects of imperatorin in the cardiovascular system and cancer. Biomedicine \& Pharmacotherapy. 2019;120:1-8.

16. Coşan DT, Saydam F, Özbayer C, Doğaner F, Soyocak A, Güneş $\mathrm{HV}$, et al. Impact of tannic acid on blood pressure, oxidative stress and urinary parameters in L-NNA-induced hypertensive rats. Cytotechnology. 2015;67(1): 97-105.

17. Hossain MA, Rahman SMM. Isolation and characterisation of flavonoids from the leaves of medicinal plant Orthosiphon stamineus. Arabian Journal of Chemistry. 2015;8: 218-21.

18. Chen Y, Jin Y, Chen Y, Jin Y, Liu X, Wang L. A Novel HPLC Method to Analyze Imperatorin and isoimperatorin of Angelica dahurica oils obtained by supercritical fluid extraction. Journal of Liquid Chromatography \& Related Technologies. 2009;32(16): 2384-95.

19. Yam MF, Mohamed EAH, Ang LF, Pei L, Darwis Y, Mahmud R, et al. A simple isocratic HPLC method for the simultaneous determination of Sinensetin, Eupatorin, and 30-hydroxy-5,6,7,40tetramethoxyflavone in Orthosiphon stamineus extracts. J Acupunct Meridian Stud. 2012;5(4):176-82.

20. Mirsad C, Lejla K. Spectrophotometric evaluation of tannin content in domestic beer samples with fe(iii) and 1,10-phenanthroline. Journal of Pharmacy and Pharmacology. 2020;8:7-12.

21. Shafaei A, Khan MdSS, Aisha AFA, Hamdan MR, Mordi MN, Ismai Z. Flavonoids-rich Orthosiphon stamineus extract as new candidate for angiotensin i-converting enzyme inhibition: A molecular docking study. Molecules.2016;21:1-16.

22. Moon TM, Tykocki NR, Sheehe JL, Osborne BW, Tegge W, Brayden JE, et al. Dostmann WR. Synthetic peptides as cGMP-independent activators of cGMP-dependent protein kinase la. Chemistry \& Biology. 2015;22:1653-61.

23. Delacroix S, Chokka RG, Worthley SG. Hypertension: Pathophysiology and treatment. J Neurol Neurophysiol 2014;5(6):1-8.

24. Cao Y, Zhang Y, Wang N, He L. Antioxidant effect of imperatorin from Angelica dahurica in hypertension via inhibiting NADPH oxidase activation and MAPK pathway. J Am Soc Hypertens. 2014;8(8):527-36.

25. Dhianawaty D, Ruslin. Total polyphenol content and antioxidant activity of methanol extract of Imperata cylindrica (L) Beauv. (alangalang) root. Bandung Medical Journal. 2015;47(1):60-4.

26. Putri Chairani Eyanoer, Yuandani, Editors. Kandungan total flavonoid dari ekstrak metanol akar Imperata cylindrica (L) Beauv. (Alanglang). Prosiding Seminar Nasional Tanaman Obat Indonesia Ke 54; 2018 April 26-27; Medan, Indonesia: Talenta Publisher; 2018.

27. Yesudas R, Gumaste U, Snyder R, Thekkumkara T. Tannic acid down-regulates the angiotensin type 1 receptor through a MAPKdependent mechanism. Molecular Endocrinology. 2012;3:458-70. 


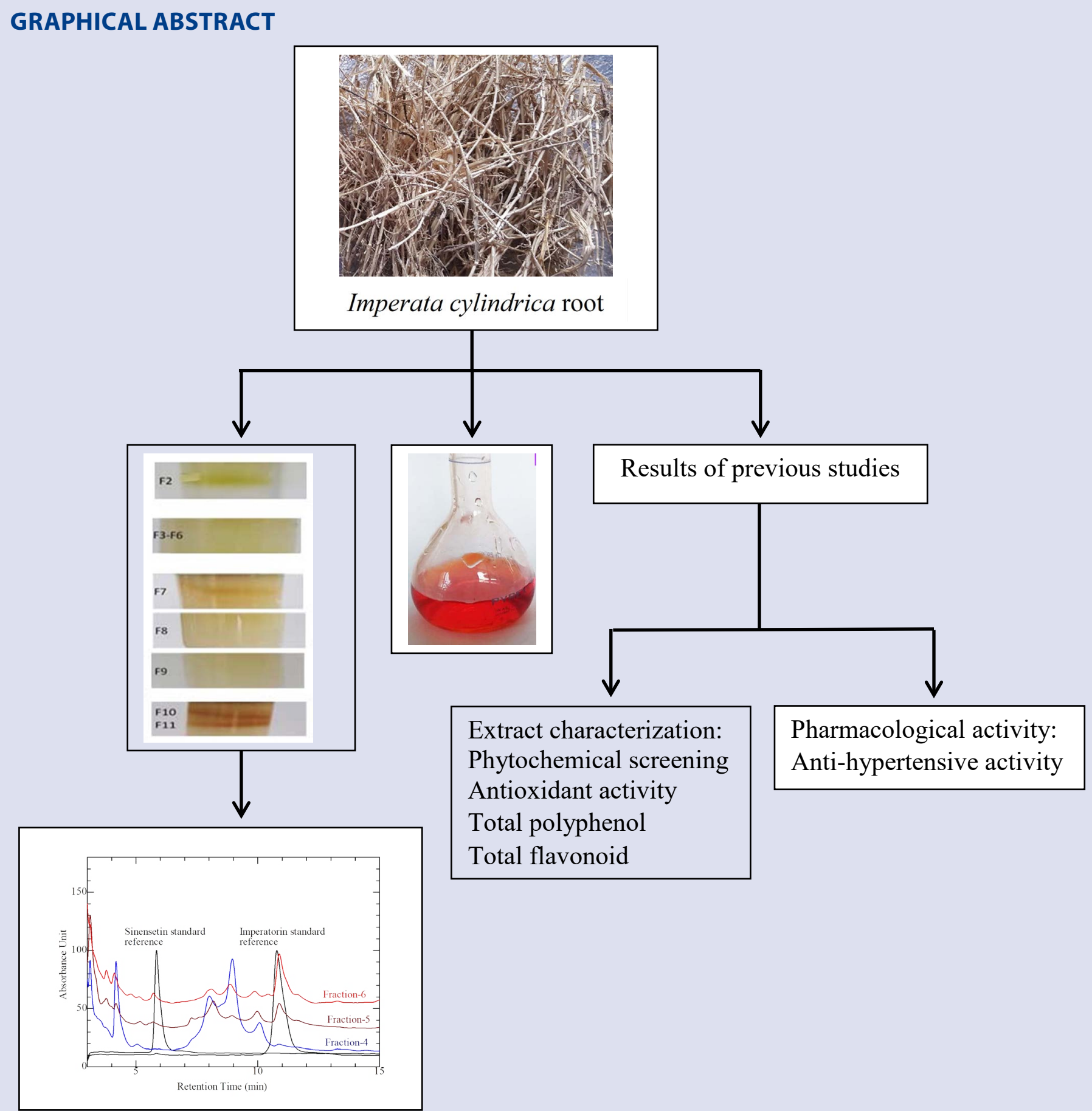




\section{ABOUT AUTHORS \\ Diah Dhianawaty: Lecturer-Researcher in the Department of Biomedical SciencesDivision of Biochemistry and Molecular Biology, Faculty of Medicine, Universitas Padjadjaran, Bandung, West Java, Indonesia.}
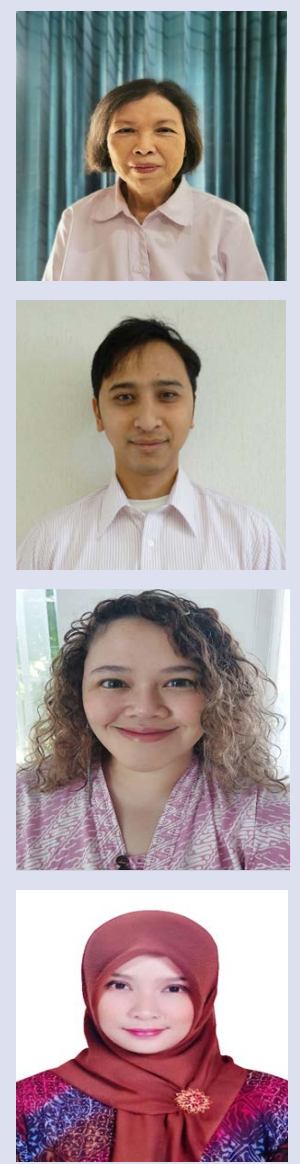

Mas Rizky Anggun Adipurna Syamsunarno: Lecturer Researcher in the Department of Biomedical Sciences, Division of Biochemistry and Molecular Biology, Faculty of Medicine, Universitas Padjadjaran, Bandung, West Java, Indonesia.

Resti Gradia Dwiwina: Lecturer-Researcher in the Department of Biomedical Sciences, Division of Cell Biology, Faculty of Medicine, Universitas Padjadjaran, Bandung, West Java, Indonesia.

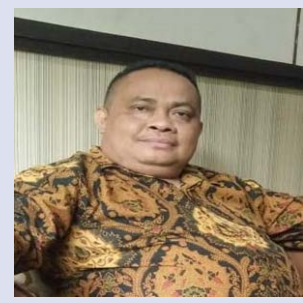

R. Anita Indriyanti: Lecturer in Pharmacology Departement, Faculty of Medicine, Universitas Islam Bandung, West Java, Indonesia.

\section{Ruslin:}

*Lecturer in Faculty of Pharmacy, Halu Oleo University, Kendari, Southeast Sulawesi, Indonesia.

*Dean of Faculty of Pharmacy, Halu Oleo University, Kendari, Southeast Sulawesi, Indonesia.

Cite this article: Dhianawaty D, Syamsunarno MRAA, Dwiwina RG, Indriyanti RA, Ruslin. Separation and Quantification of Sinensetin, Imperatorin, and Total Tannin Content as Active Phytoconstituents of Methanol Extract of Imperata cylindrica Root from Kendari. Pharmacogn J. 2021;13(5): 1216-1224. 